Article

\title{
The Shape-Memory Effect of Hindered Phenol (AO-80)/Acrylic Rubber (ACM) Composites with Tunable Transition Temperature
}

\author{
Shi-kai Hu ${ }^{1,2}$, Si Chen ${ }^{1}$, Xiu-ying Zhao ${ }^{1, *}$, Ming-ming Guo ${ }^{1,2}$ and Li-qun Zhang ${ }^{1}$ \\ 1 Key Laboratory of Beijing City on Preparation and Processing of Novel Polymer Materials, Beijing \\ University of Chemical Technology, Beijing 100029, China; 2017400073@mail.buct.edu.cn (S.-k.H.); \\ aircs123@163.com (S.C.); guomm57@swu.edu.cn (M.-m.G.); zhanglq@mail.buct.edu.cn (L.-q.Z.) \\ 2 SINOPEC Beijing Research Institute of Chemical Industry, Beijing 100013, China \\ * Correspondence: zhaoxy@mail.buct.edu.cn; Tel.: +86-10-6443-4860
}

Received: 31 October 2018; Accepted: 26 November 2018; Published: 4 December 2018

\begin{abstract}
To broaden the types and scope of use of shape-memory polymers (SMPs), we added the hindered phenol 3,9-bis[1,1-dimethyl-2-\{b-(3-tert-butyl-4-hydroxy-5-methylphenyl)propionyloxy\}ethyl] -2,4,8,10-tetraoxaspiro-[5,5]-undecane (AO-80), which comprises small organic molecules, to acrylic rubber (ACM) to form a series of AO-80/ACM rubber composites. The structural, thermal, mechanical property, and shape-memory properties of the AO-80/ACM rubber composites were investigated. We identified the formation of intra-molecular hydrogen bonding between - $\mathrm{OH}$ of $\mathrm{AO}-80$ and the carbonyl groups and the ether groups of ACM molecules. The amount of AO- 80 used can be adjusted to tailor the transition temperature. AO-80/ACM rubber composites showed excellent shape recovery and fixity. The approach for adjusting the transition temperature of AO-80/ACM rubber composites provides remarkable ideas for the design and preparation of new SMPs.
\end{abstract}

Keywords: acrylic rubber; shape-memory polymer; hindered phenol; hydrogen bonding

\section{Introduction}

Shape-memory materials (SMMs) can change from one pre-determined shape to another in response to a certain stimulus [1,2]. Research on shape-memory polymers (SMPs) can be fundamental and applied. SMPs possess many advantages over their well-investigated metallic counterparts, shape-memory alloys; these advantages include excellent processability, light weight, and notable flexibility in terms of material design [3-5]; SMP applications include medical devices, actuators, sensors, artificial muscles, switches, smart textiles, and self-deployable structures [4-7]. SMPs can return into an original shape upon the application of stimuli, such as temperature [8-10], humidity [11,12], light [13-16], electricity [8,17-20], pH [15,21-24], and irradiation. This memory phenomenon is because a polymer network has reversible and fixed phases. The reversible phases can be shaped under certain conditions. Reversible phases use ionic bond [1,25], vitrification [25,26], reversible crystallization [27], hydrogen bond [28,29], or supramolecular interactions [30,31] to maintain this metastable shape until an activation energy is used to facilitate a return to the original shape. The fixed phases allow deformation but hold the relative location of the chains. Fixed phases include physical and covalent cross-links, such as crystalline or glassy domains in polymers, or supramolecular interactions [32]. For thermally induced SMPs, when the deformation of SMP is above its switch transition temperature $\left(T_{\text {trans }}\right)$ and then cooled below $T_{\text {trans }}$, most internal stress can be stored in cross-linking structure; by heating the SMP above its $T_{\text {trans, }}$, the SMP recovers its original shape by releasing the internal stress [33,34]. When reheated above $T_{\text {trans }}$ without stress, the cross-linking phase assumes its permanent shape. $T_{\text {trans }}$ can either be the glass transition 
temperature $\left(T_{g}\right)$ or melting temperature $\left(T_{m}\right)$ of polymers. In general, the temperature province of $T_{\text {trans }}$ of current SMMs reaches above room temperature. However, in specific conditions, such as deep-sea and polar region explorations, $T_{\text {trans }}$ of SMMs should be lower than room temperature and can be adjusted and controlled by specific methods. A critical parameter for SMPs lies in its shape memory $T_{\text {trans }}$. For an amorphous SMP polymer, it is important to develop new methods to tailor its $T_{g}$, which corresponds to its shape memory $T_{\text {trans }}$. Zhao et al. created a nano- or molecule-scale-hindered phenol and polar rubber compound. Their research indicated that $T_{g}$ of the developed material could be tailored by changing the kind and dosage of small organic molecule-hindered phenol $[35,36]$. This phenomenon was attributed to hydrogen bonding between hindered phenol 3,9-bis[1,1-dimethyl-2-\{b-(3-tert-butyl-4-hydroxy-5-methylphenyl)propionyloxy\}ethyl]-2,4,8,10 -tetraoxaspiro-[5,5]-undecane $(\mathrm{AO}-80)$ and polar rubber. Such interactions will result in the molecular-level dispersion of AO-80 in CPE and rubber matrix and enhancement of intermolecular friction, which will further increase $T_{g}$. It is well known that typical epoxy-based materials which have been applied extensively in coatings, adhesives, and matrix material for structural composites are rigid with relatively low failure strains. There are many references regarding shape-memory epoxy composites that all have good shape memory with a high shape fixity $\left(R_{f}\right)$ ratio and high shape recovery ratio $\left(R_{r}\right)$, but these composites all have a short elongation at break [37-42]. In this study, AO- 80 had been studied to prepare AO-80/acrylic rubber (ACM) nanocomposites with high failure strains compared to shape-memory epoxy composites. The structure of AO-80 is shown in Figure 1. AO-80/ACM rubber nanocomposites possibly possess remarkable filler/matrix interfacial properties because the AO- 80 molecule features numerous polar functional groups (hydroxyl and carbonyl) that can form strong intermolecular interactions with ACM. An elastomer will exhibit shape-memory functionality when the material can be stabilized in the deformed state in a temperature range that is relevant for particular applications. Similar to normal polymers, SMPs also possess 3D molecular network-like architectures. ACM can exhibit 3D network structures after crosslinking. These cross-linked structures ensure that the polymer can maintain a stable shape at the macroscopic level by enabling the original and recovered shapes. This system also features a $T_{g}$ below the room temperature, and temperature can be adjusted and controlled within a particular scope by incorporating small organic molecules to increase $T_{g}[35,36]$, which will broaden the kind and scope of use of SMPs. In this study, we designed a series of AO-80/ACM rubber composites with high failure strains, the $T_{\text {trans }}$ of which can be tailored by adding a dosage of small organic molecule-hindered phenol. No study or similar work has investigated the shape-memory effect of AO-80/ACM rubber composites, thereby broadening the list of SMPs with excellent shape-memory properties.

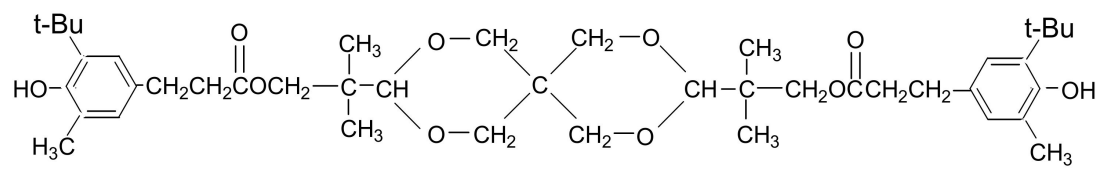

Figure 1. Chemical structure of hindered phenol 3,9-bis[1,1-dimethyl-2-\{b-(3-tert-butyl-4-hydroxy-5 -methylphenyl)propionyloxy\}ethyl]-2,4,8,10-tetraoxaspiro-[5,5]-undecane (AO-80).

\section{Materials and Methods}

\subsection{Materials}

ACM (AR-801) was provided by Tohpe Corp (Sakai, Japan). AO-80 was obtained from Asahi Denka (Tokyo, Japan). Other ingredients and chemicals were obtained from China and were used as received.

\subsection{Sample Preparations}

AO-80/ACM rubber composites were obtained as follows: (1) After ACM was kneaded for 3 min, AO-80 (without previous treatment) was added into ACM. (2) After these mixtures were kneaded 
for $5 \mathrm{~min}$, the AO-80/ACM mixtures were blended with compounding and crosslinking additives, including $5.0 \mathrm{phr}$ of zinc oxide(CAS No:1314-13-2), $1.0 \mathrm{phr}$ of stearic acid(CAS No: 57-11-4), $0.5 \mathrm{phr}$ of potassium stearate(CAS No: 593-29-3), 4 phr of sodium stearate(CAS No: 822-16-2), and $0.5 \mathrm{phr}$ of sulfur(CAS No: 7704-34-9). The mixtures were then kneaded for $10 \mathrm{~min}$. The mixtures of AO-80/ACM were kept for at least $24 \mathrm{~h}$. (3) Finally, the mixtures of AO-80/ACM were set at $180^{\circ} \mathrm{C}$ and $15 \mathrm{MPa}$ for $20 \mathrm{~min}$ and then naturally cooled down to prepare AO-80/ACM rubber composites.

\subsection{Methods}

The structure, shape-memory properties, and mechanical and thermal properties of AO-80/ACM rubber composites were systematically evaluated by differential scanning calorimetry (DSC), dynamic mechanical analysis (DMA), and Fourier-transform infrared (FT-IR) spectroscopy. The DSC curves were acquired from $-60{ }^{\circ} \mathrm{C}$ to $150{ }^{\circ} \mathrm{C}$ at a rate of $10{ }^{\circ} \mathrm{C} / \mathrm{min}$ with a STAR system calorimeter (Mettler-Toledo Co., Zurich, Switzerland). FT-IR spectra were acquired by using a Spectra-Tech ATR attachment to scan the samples.

The static mechanical properties of AO-80/ACM rubber composites were determined according to ASTM D638 by using a CMT4104 Electrical Tensile Tester (SANS Testing Machine Co., ShenZhen, China) at a rate of $500 \mathrm{~mm} / \mathrm{min}$ at room temperature. The strip dimensions for testing were $20 \mathrm{~mm}$ in length, $6 \mathrm{~mm}$ in width, and $2 \mathrm{~mm}$ in thickness. Hardness was tested according to ASTM D2240-2015.

The shape-memory effect analysis of AO-80/ACM rubber composites was investigated on the DMA Q800 (TA Instruments, New Castle, DE, USA) using controlled-force mode with rectangular samples (6 $\mathrm{mm}$ in width and $2 \mathrm{~mm}$ in thickness). Prior to the investigation, the temperature was adjusted to an equilibration at $T_{\text {trans }}+20^{\circ} \mathrm{C}$ for $10 \mathrm{~min}$. In step 1 (deformation), the sample was stretched to a designed value ( $\varepsilon=55 \%, \varepsilon=100 \%, \varepsilon=130 \%$ ) by ramping the force from a preload value of $0.005 \mathrm{~N}$ at a rate of $0.5 \mathrm{~N} / \mathrm{min}$. In step 2 (cooling), the specimen was cooled to fix the deformed sample under constant force at the rate of $3{ }^{\circ} \mathrm{C} / \mathrm{min}$ to $T_{\text {trans }}-20^{\circ} \mathrm{C}$. In step 3 (unloading and fixing), the force of the specimen was unloaded at a rate of $0.5 \mathrm{~N} / \mathrm{min}$ to a preload value $(0.005 \mathrm{~N})$. Then, an equilibration at $T_{\text {trans }}-20{ }^{\circ} \mathrm{C}$ for $10 \mathrm{~min}$ to ensure shape fixing was performed. In the final step (recovery), the specimen was reheated to $T_{\text {trans }}+60^{\circ} \mathrm{C}$ at the rate of $3^{\circ} \mathrm{C} / \mathrm{min}$ [37]. All experiments were carried out three times successively and the average results between second and third cycles are shown in the paper. From the curves, the shape recovery ratio $\left(R_{r}\right)$ and the shape fixity ratio $\left(R_{f}\right)$ for the shape-memory effect were computed as follows:

$$
\begin{gathered}
\text { Shape recovery : } R_{r}(N)=\frac{\varepsilon_{m}-\varepsilon_{p}(N)}{\varepsilon_{m}-\varepsilon_{p}(N-1)}, \times 100 \% \\
\text { Shape fixity : } R_{f}(N)=\frac{\varepsilon_{u}(N)}{\varepsilon_{m}(N)} \times 100 \%
\end{gathered}
$$

where $\varepsilon_{m}, \varepsilon_{u}$ and $\varepsilon_{p}$ are strains after the step of cooling, unloading, and recovery process, respectively. $N$ refers to a consecutive number in a cyclic shape-memory measurement.

Dynamic mechanical properties were investigated on a DMA (Rheometric Scientific Co., Piscataway, NJ, USA). The strip dimensions for testing were $20 \mathrm{~mm}$ in length, $6 \mathrm{~mm}$ in width, and $2 \mathrm{~mm}$ in thickness. The curves of $\mathrm{E}^{\prime}-\mathrm{T}$ were acquired from $-60{ }^{\circ} \mathrm{C}$ to $150{ }^{\circ} \mathrm{C}$ at a rate of $3{ }^{\circ} \mathrm{C} / \mathrm{min}$ and with a frequency of $1 \mathrm{~Hz}$ at an amplitude of $\varepsilon=0.3 \%$.

Shape recovery observations of the AO-80/ACM rubber composites were carried out in water. The composites were cut into rectangular strips with dimensions of $100.0 \mathrm{~mm} \times 10.0 \mathrm{~mm} \times 2.0 \mathrm{~mm}$. The rectangular strips were fixed in a temporary shape at $T_{\text {high }}$ and then cooled down to $T_{\text {low }}$. The rectangular strips in temporary shape were placed in a water bath at $T_{\text {high }}$ while recording images of shape recovery using a video camera at a rate of 20 frames/s. Among the aforementioned procedure/conditions, $T_{\text {high }}$ was equal to $T_{\text {trans }}+20^{\circ} \mathrm{C}$, and $T_{\text {low }}$ was equal to $T_{\text {trans }}-20^{\circ} \mathrm{C}$. 


\section{Results}

\section{1. $T_{g}$ of AO-80/ACM Rubber Composites}

Figure 2 shows that the neat $\mathrm{ACM}$ featured a $T_{g}$ of approximately $-11{ }^{\circ} \mathrm{C}$. Compared with the neat $\mathrm{ACM}, \mathrm{AO}-80 / \mathrm{ACM}$ composites showed a $T_{g}$ between those of neat $\mathrm{ACM}$ and quenched AO-80(40.9) [36]. $T_{g}$ of AO-80/ACM rubber composites shifted from $-11^{\circ} \mathrm{C}$ to $10{ }^{\circ} \mathrm{C}$ when the dosage of AO-80 was added from zero $\mathrm{phr}$ to one hundred phr. The DSC curves of the composites showed neither $T_{g}$ peak nor melting of AO-80 [36,43], which suggest that dispersion of AO-80 in ACM was at the molecular level by blending, and $\mathrm{AO}-80 / \mathrm{ACM}$ rubber composites were successfully prepared as expected. Strong intermolecular interactions were formed between AO- 80 molecules and polar functional groups (ester and ether groups) of ACM. Hydrogen bonding between ACM and AO- 80 are analyzed later. With both polar molecules, intermolecular interactions significantly hindered the slide of ACM chain and increased $T_{g}$ of ACM composites.

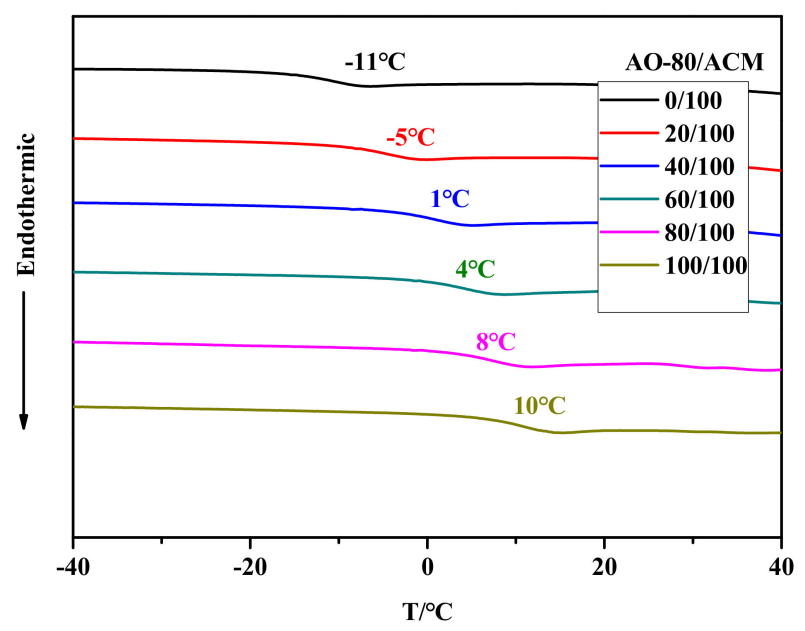

Figure 2. DSC curves of AO-80/acrylic rubber (ACM) rubber composites.

\subsection{FT-IR of AO-80/ACM Rubber Composites}

Interactions between different functional groups can be investigated through molecular dynamics simulation and FT-IR [44,45]. Figure 3 shows the FT-IR/ATR spectra of neat ACM and AO-80/ACM rubber composites. Figure 3a shows that the FT-IR/ATR spectra of all AO-80/ACM rubber composites indicate significantly wide peaks at $1135 \mathrm{~cm}^{-1}$ to $1195 \mathrm{~cm}^{-1}$, which were assigned to C-O-C bending vibration and symmetric and antisymmetric stretching vibrations. The peak position gradually shifted to a higher wave number from $1158.5 \mathrm{~cm}^{-1}$ to $1163 \mathrm{~cm}^{-1}$ when the dosage of AO- 80 was added from zero $\mathrm{phr}$ to one hundred phr, determining that $-\mathrm{O}-$ of $\mathrm{C}-\mathrm{O}-\mathrm{C}$ can bond with-OH of AO-80. Figure $3 \mathrm{~b}$ shows the composition dependence of FT-IR spectra for the $-\mathrm{C}=\mathrm{O}$ stretching regions of AO-80/ACM rubber composites. As AO- 80 content increased, the $-\mathrm{C}=\mathrm{O}$ peak position shifted to a higher wave number from $1730.0 \mathrm{~cm}^{-1}$ to $1732.0 \mathrm{~cm}^{-1}$ when the dosage of AO-80 was added from zero phr to one hundred phr. Studies reported that hydrogen-bonded vibration will present a frequency shift $[35,36]$. Figure $3 \mathrm{c}$ shows the $-\mathrm{OH}$ stretching regions of AO-80/ACM rubber composites. The position of- $\mathrm{OH}$ peak shifted to a lower wave number from $3555.1 \mathrm{~cm}^{-1}$ to $3498.7 \mathrm{~cm}^{-1}$ when the dosage of AO- 80 was added from zero $\mathrm{phr}$ to one hundred phr. The hydrogen bonding between carbonyl and ether groups of segments of ACM and -OH groups of AO- 80 was observed. The total frequency shift as a measure of the strength of hydrogen bonding is generally accepted [46-48]. Thus, these results indicate that as the dosage of AO- 80 increased, the strength of the hydrogen bonding among functional groups between $\mathrm{ACM}$ and AO-80 improved. The result corroborates that the $T_{g}$ of AO-80/ACM rubber composites increased with the dosage of AO-80, increasing because of hydrogen bonding. Figure 4 shows the possible hydrogen bonding of AO-80/ACM rubber composites. 

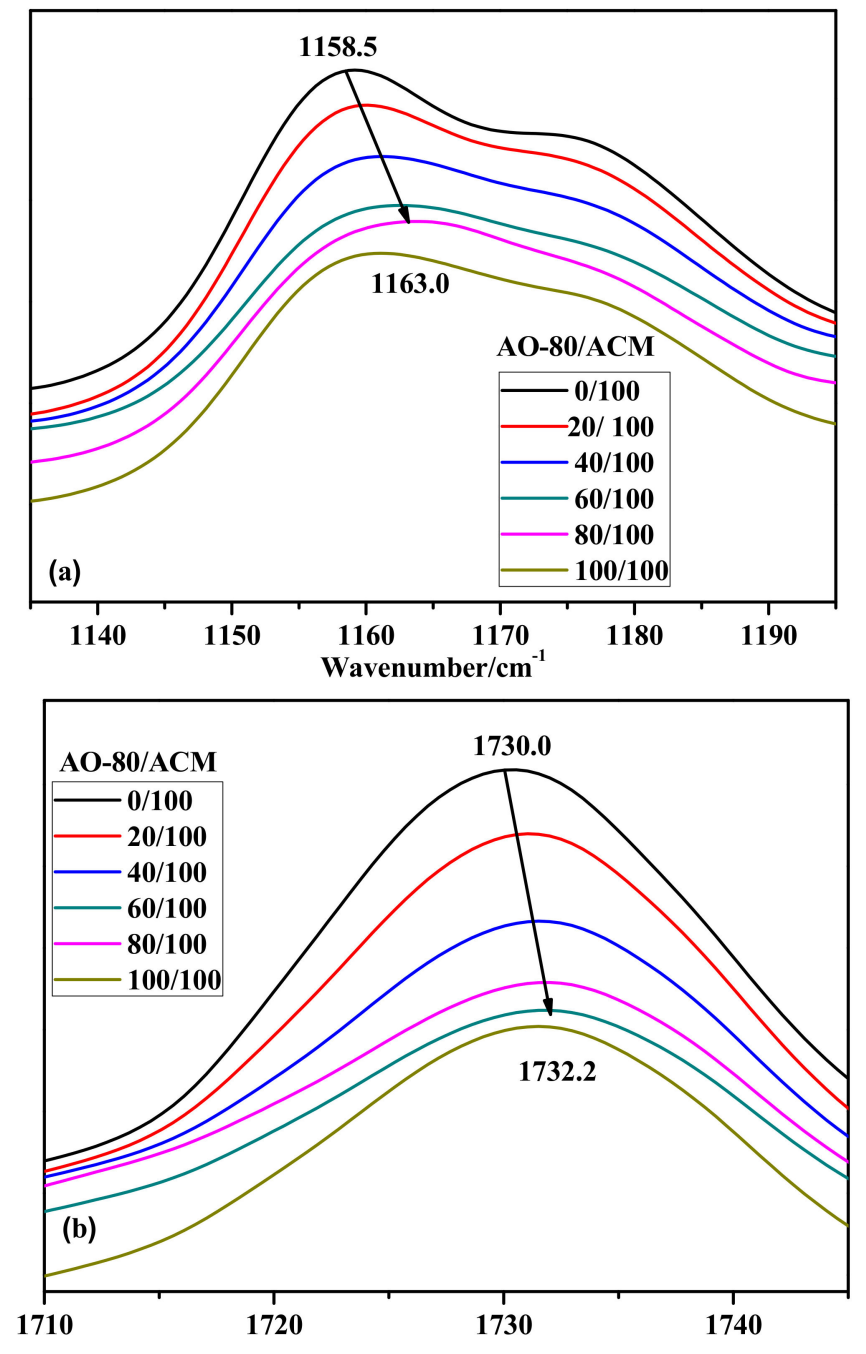

Wavenumber $/ \mathrm{cm}^{-1}$

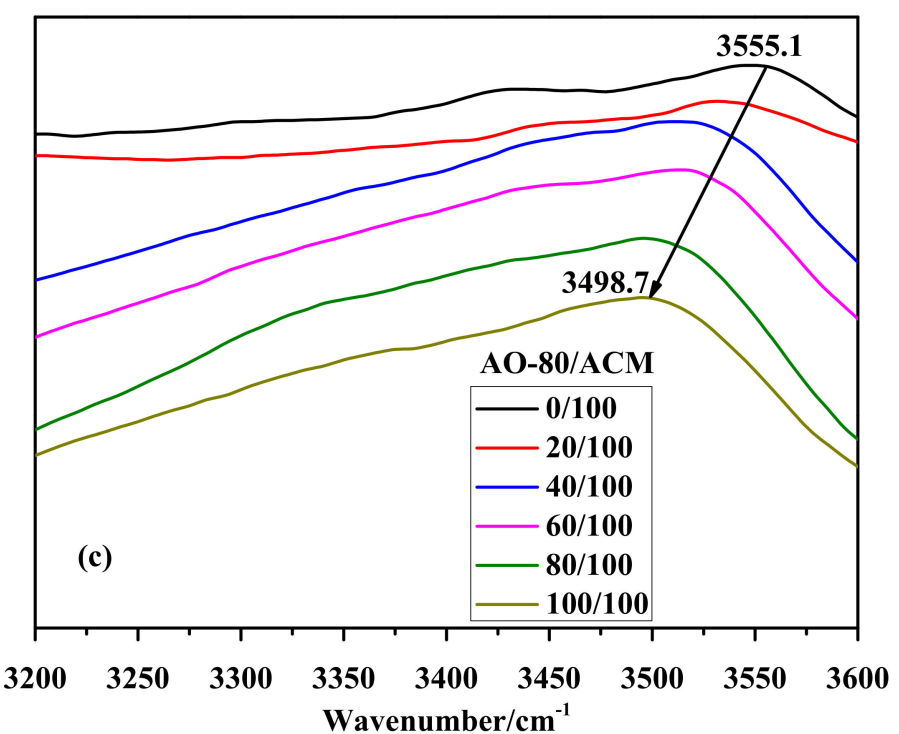

Figure 3. FT-IR spectra acquired at: (a) $1135 \mathrm{~cm}^{-1}$ to $1195 \mathrm{~cm}^{-1}$; (b) $1710 \mathrm{~cm}^{-1}$ to $1745 \mathrm{~cm}^{-1}$; and (c) $3200 \mathrm{~cm}^{-1}$ to $3600 \mathrm{~cm}^{-1}$ region for AO-80/ACM rubber composites. 


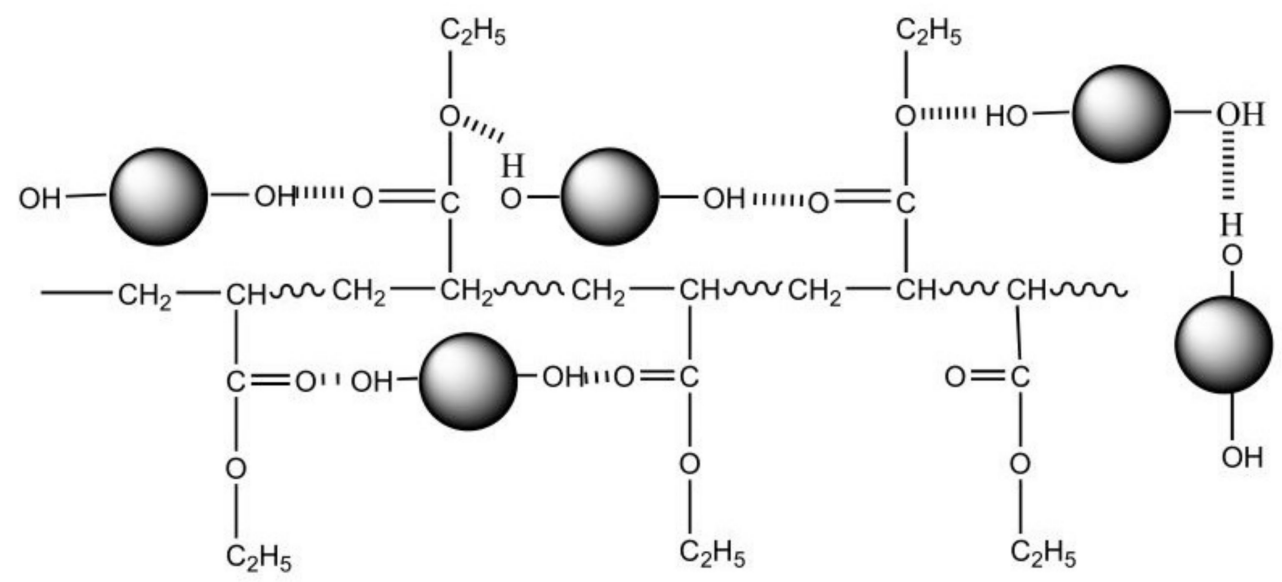

AO-80:

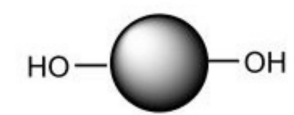

Hydrogen bond: '"'!

Figure 4. Possible hydrogen bond between AO-80 and ACM.

\subsection{Static Mechanical Properties of AO-80/ACM Rubber Composites}

The results of the tensile testing of neat ACM and AO-80/ACM rubber composites are shown in Figure 5 and the acquired data is summarized in Table 1 . The elongation and tensile strength at break of the neat ACM were $210 \%$ and $1.47 \mathrm{MPa}$, respectively. All of the AO-80/ACM rubber composites with a content of AO-80 above forty phr had much longer elongation and higher tensile strength at break than ACM. This was because AO- 80 had a reinforcement effect when AO-80 was added over $40 \mathrm{phr}$ and the strength of hydrogen bonding among functional groups between ACM and AO- 80 was improved when the AO- 80 content was added increasingly.

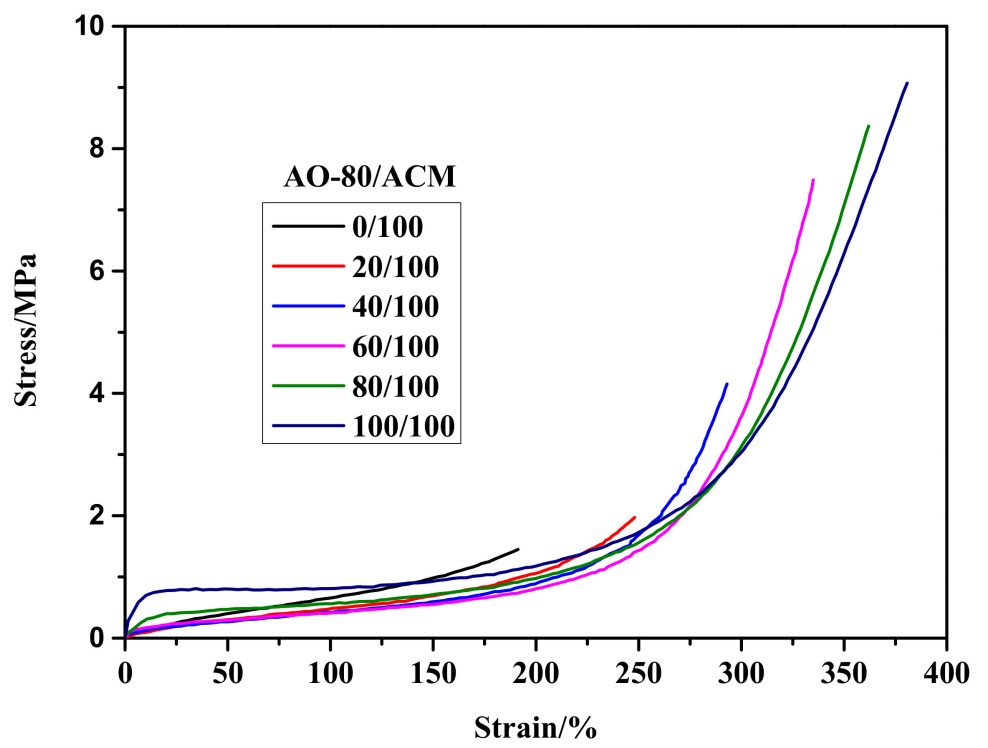

Figure 5. Stress-strain curves of ACM and AO-80/ACM rubber composites. 
Table 1. Mechanical properties of AO-80/ACM rubber composites.

\begin{tabular}{ccccccc}
\hline \multirow{2}{*}{ Properties } & \multicolumn{7}{c}{ Loadings of AO-80/phr } \\
\cline { 2 - 7 } & $\mathbf{0}$ & $\mathbf{2 0}$ & $\mathbf{4 0}$ & $\mathbf{6 0}$ & $\mathbf{8 0}$ & $\mathbf{1 0 0}$ \\
\hline Hardness (Shore A) & $41 \pm 0$ & $48 \pm 0$ & $68 \pm 0$ & $78 \pm 0$ & $93 \pm 0$ & $95 \pm 0$ \\
Tensile strength (MPa) & $1.5 \pm 0.2$ & $1.9 \pm 0.1$ & $4.0 \pm 0.2$ & $7.7 \pm 0.1$ & $8.2 \pm 0.1$ & $9.2 \pm 0.2$ \\
Elongation at break (\%) & $210 \pm 9$ & $248 \pm 11$ & $295 \pm 12$ & $336 \pm 8$ & $369 \pm 8$ & $377 \pm 5$ \\
\hline
\end{tabular}

\subsection{Shape-Memory Effect of AO-80/ACM Rubber Composite}

Figure 6 depicts the 3D $\varepsilon-\mathrm{T}-\sigma$ curves of various compositions for AO-80/ACM rubber composites. The results showed that the samples were generally further deformed because of loading during the cooling/fixing step after deformation, and the $T_{g}$ of AO-80/ACM rubber composites increased with an increasing dosage of AO-80; in other words, the $T_{\text {trans }}$ of AO-80/ACM rubber composites also increased with increasing AO-80. All samples exhibited excellent shape recovery, as shown in Figure 6. All the samples presented a high shape fixing ratio and recovery ratio when they were stretched to a given strain (100\%). $R_{r}$ and $R_{f}$ were both above $99 \%$. Figure 7 plots the 3D $\varepsilon-\mathrm{T}-\sigma$ curves of five cycles for AO-80/ACM (40/100) rubber composite. The 3D $\varepsilon-\mathrm{T}-\sigma$ curves of AO-80/ACM (40/100) rubber composites were similar with different cycles. Different cycles all showed high shape fixing and recovery rates. The results showed the repeatability of AO-80/ACM rubber composites as shape-memory materials were excellent. The excellent repeatability of AO-80/ACM rubber composites was due to good elasticity of samples. Figure 8 plots the $3 \mathrm{D} \varepsilon-\mathrm{T}-\sigma$ curves of different strains (deformation) for AO-80/ACM (60/100) rubber composite. All the diagrams show high shape fixing and recovery ratio when the given strains were $55 \%, 100 \%$, and $130 \% . R_{r}$ reached above $99 \%$, and $R_{f}$ was above $99 \%$. The results show that the range of deformation for the AO- $80 / \mathrm{ACM}$ rubber composites as shape-memory materials is broad, which is due to high elongation at break of AO-80/ACM rubber composites. Figure 9 displays the $R_{r}$-T curves of AO-80/ACM rubber composites with various compositions. A significant portion of prestrain was recovered in all samples within the temperature range of $T_{10}-T_{90}$. With increasing AO-80, the recovery temperature, $T_{10}\left(R_{r}=10 \%\right)$, $T_{50}\left(R_{r}=50 \%\right), T_{90}\left(R_{r}=90 \%\right)$ increased, which was due to intermolecular interactions significantly hindering the slide of ACM chain and increasing the $T_{g}$ ( $T_{\text {trans }}$ ) of AO-80/ACM rubber composites. Figures 6-9 show that AO-80/ACM rubber composites exhibit excellent shape-memory behavior.

The possible molecular mechanism of AO-80/ACM rubber composites is that AO-80/ACM rubber composites consist of molecular switches that are temperature-sensitive netpoints. The permanent shape in AO-80/ACM rubber composites was determined by netpoints that are cross-linked by the cross-linking agent. The temporary shape was fixed by the vitrification of AO-80/ACM rubber composites. Samples can be deformed to a temporary shape above $T_{\text {trans }}+20^{\circ} \mathrm{C}$, and the shape can be fixed at $T_{\text {trans }}-20{ }^{\circ} \mathrm{C}$ under stress. When heated above $T_{\text {trans }}+60^{\circ} \mathrm{C}$ without stress, the specimen recovered its original shape because of the netpoints. 


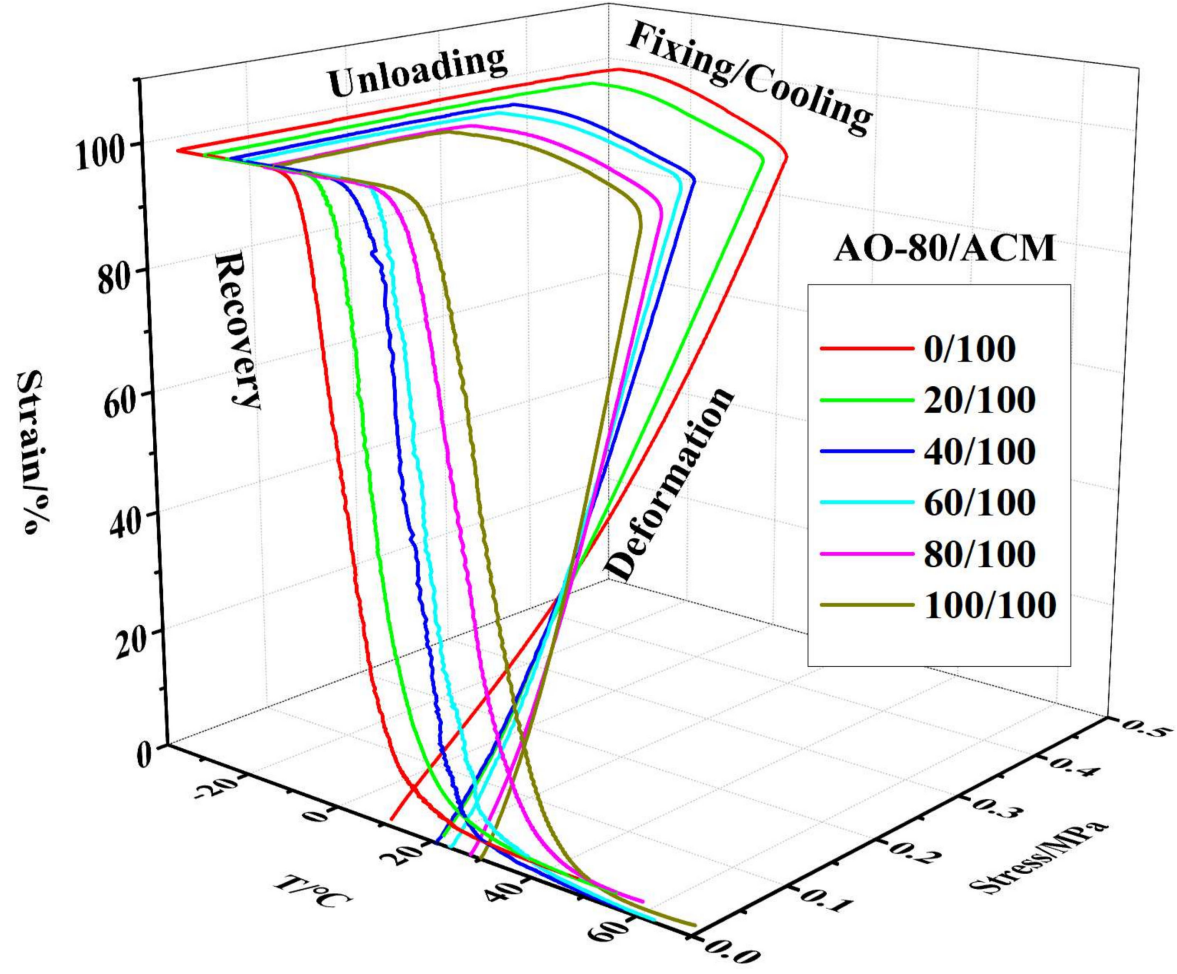

Figure 6. 3D $\varepsilon-\mathrm{T}-\sigma$ curve of various compositions for AO-80/ACM rubber composites.

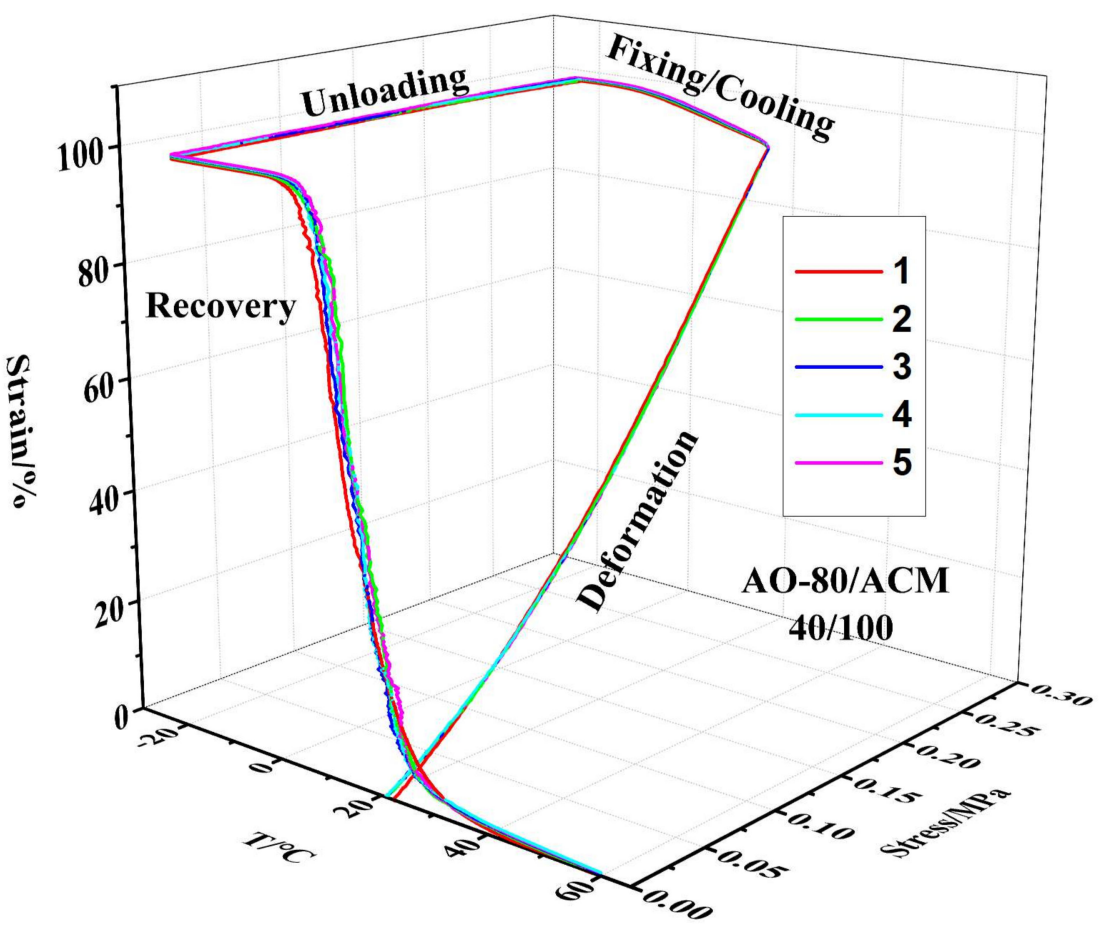

Figure 7. 3D $\varepsilon-\mathrm{T}-\sigma$ curve of five cycles for AO-80/ACM (40/100) rubber composite. 


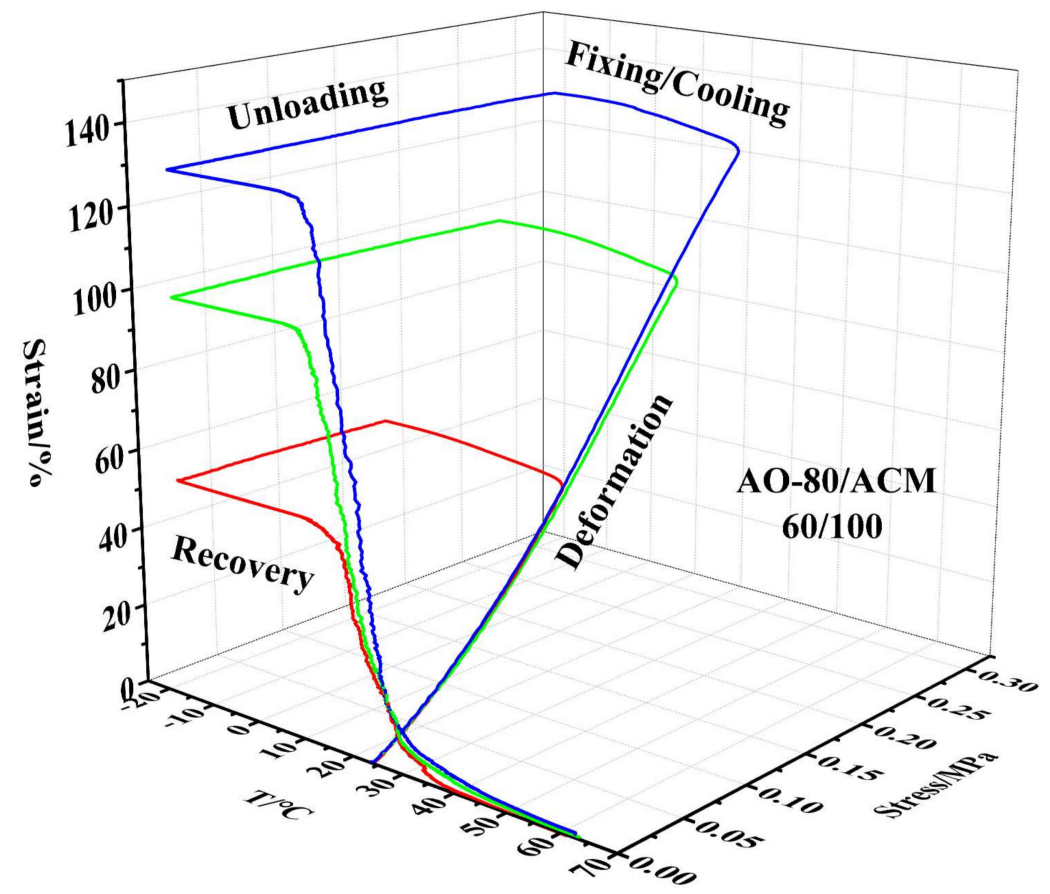

Figure 8. 3D $\varepsilon-T-\sigma$ curves of different strains (deformation) for AO-80/ACM (60/100) rubber composite.

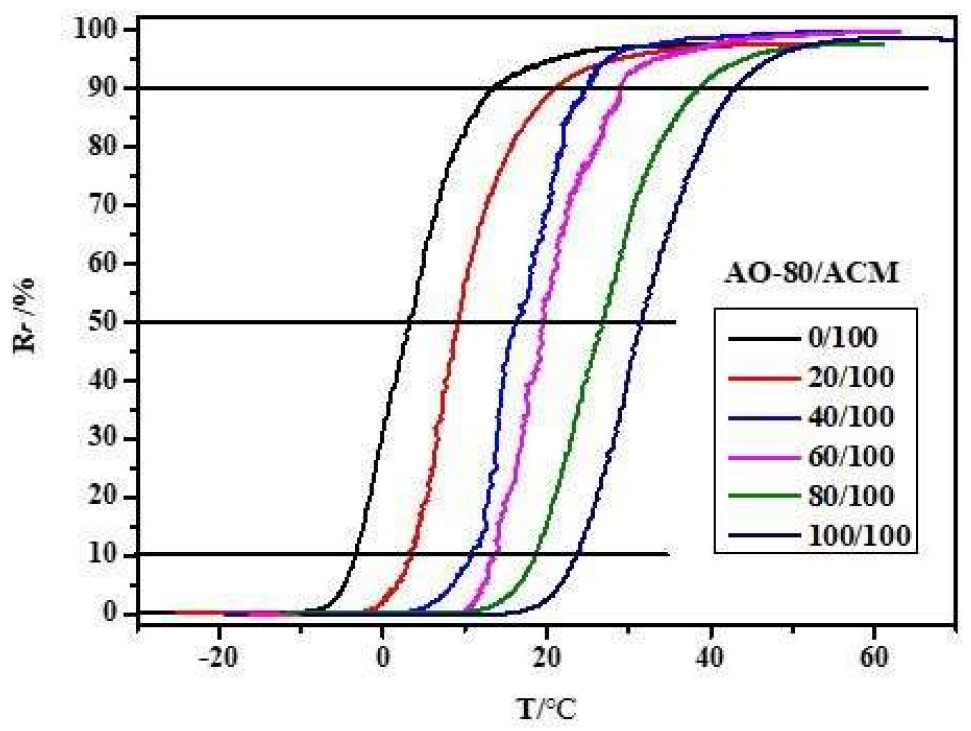

Figure 9. $R_{r}-\mathrm{T}$ curves of AO-80/ACM rubber composites.

Figure 10 shows the shape-memory recovery of AO-80/ACM (100/100) rubber composite. After placing the components in water at $20^{\circ} \mathrm{C}$, which is higher than $T_{g}$, they gradually recovered their original shape (Figure 10, $\mathrm{t}=9 \mathrm{~s}-5 \mathrm{~min}$ ). The results indicate that AO-80/ACM rubber composites exert shape-memory effects. 


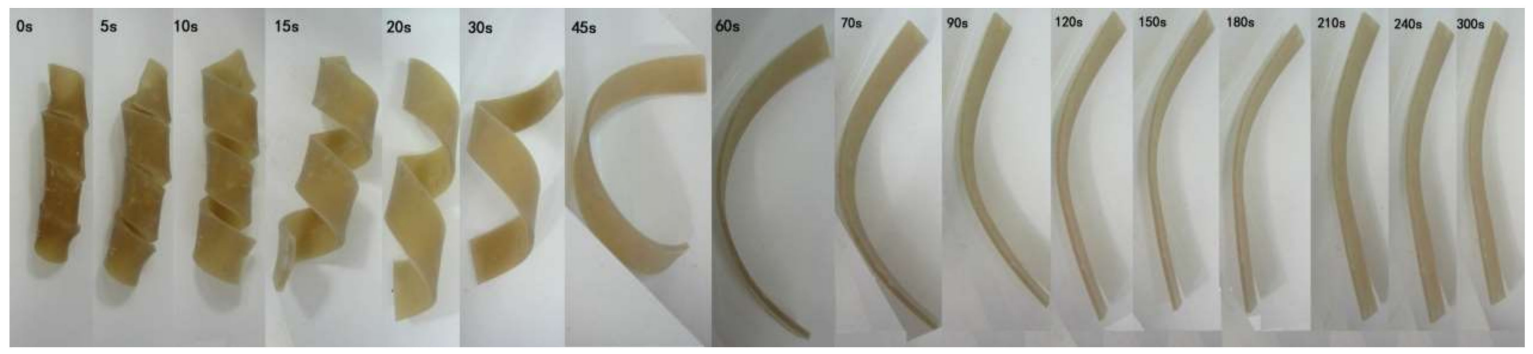

Figure 10. Shape recovery of AO-80/ACM rubber composites from a spiral-shaped temporary shape to stretched strip in water at $20^{\circ} \mathrm{C}$, which is higher than $T_{g}$.

\subsection{Dynamic Mechanical Properties of AO-80/ACM Rubber Composites}

Dynamic mechanical properties of AO-80/ACM rubber composites are shown in Figure 11. All curves have only one transition, and the curves moved toward higher temperatures with an increasing dosage of AO-80. The $\mathrm{E}^{\prime}$ values of the AO-80/ACM rubber composites were similar in the glassy regions, whereas the $\mathrm{E}^{\prime}$ values in the rubbery regions decreased with an increasing dosage of $\mathrm{AO}-80$. This was because the $\mathrm{E}^{\prime}$ values of $\mathrm{AO}-80$ were similar to that of $\mathrm{ACM}$ matrix; therefore the $\mathrm{E}^{\prime}$ values of AO-80/ACM rubber composites were similar in the glassy state. When AO-80/ACM rubber composites were in the rubbery state, temperature was higher than the $T_{g}$ of AO-80 (40.9 C) [44], the $\mathrm{AO}-80$ acted as a plasticizer after becoming soft, therefore the $\mathrm{E}^{\prime}$ values of $\mathrm{AO}-80 / \mathrm{ACM}$ rubber composites decreased. In AO-80/ACM rubber composites, all specimens showed a difference of approximately three orders of magnitude of AO-80/ACM rubber composites, which is responsible for the good recovery ratio and good shape fixity ratio for all specimens.

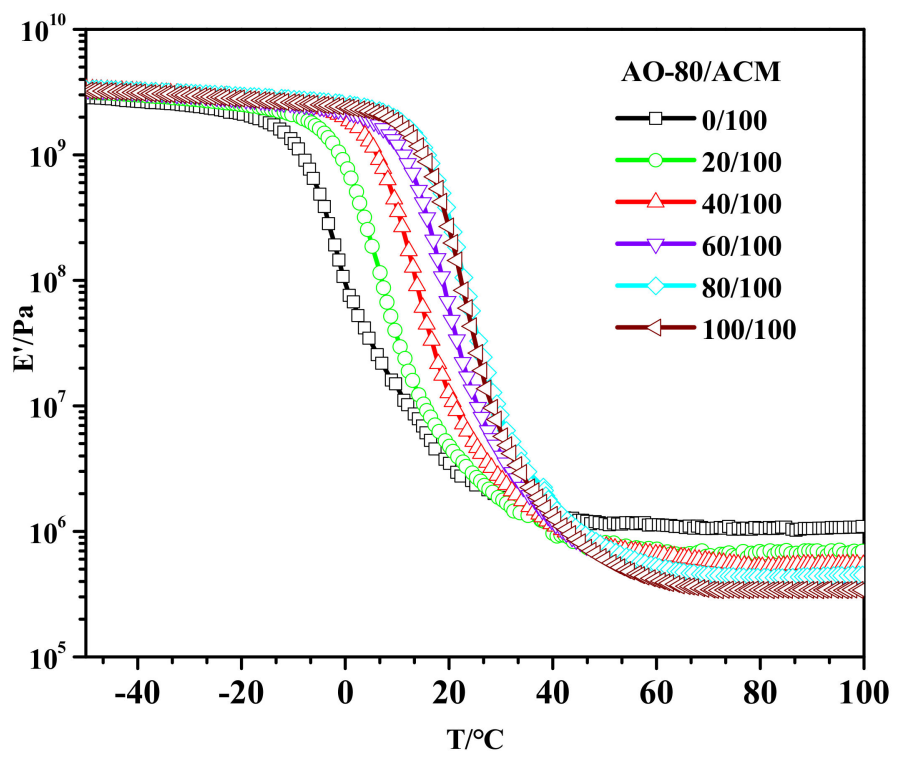

Figure 11. $\mathrm{E}^{\prime}-\mathrm{T}$ curves of AO-80/ACM rubber composites.

\section{Conclusions}

In this work, $\mathrm{AO}-80 / \mathrm{ACM}$ rubber composites were prepared. $\mathrm{AO}-80$ has been successfully used to tailor $T_{\text {trans }}$ and $T_{g}$ of AO-80/ACM rubber composites became higher with the increment in AO- 80 . The formation of hydrogen bonding between carbonyl and ether groups of ACM molecules and the $-\mathrm{OH}$ of AO-80 is responsible for the increase in $T_{g}$. Considering that $T_{\text {trans }}$ of ACM and AO-80/ACM rubber composites was related to $T_{g}$, the $T_{\text {trans }}$ of AO-80/ACM rubber composites shifted from $-11^{\circ} \mathrm{C}$ to $10{ }^{\circ} \mathrm{C}$ when the dosage of AO-80 was added from zero phr to one hundred phr. In shape-memory experiments, the composites presented a shape-memory effect, and $T_{10}, T_{50}$, and $T_{90}$ increased with 
$T_{\text {trans. }}$. Shape memory can be maintained at a wide deformation range and has good repeatability. All memory tests led to the conclusion that AO-80/ACM rubber composites feature excellent shape behavior. $R_{f}$ and $R_{r}$ of AO-80/ACM rubber composites were higher than $99 \%$ and $99 \%$, respectively. The aforementioned approaches of tuning the transition temperature of developed composites can be potentially applied to other polymer systems.

Author Contributions: X.-y.Z. conceived and designed the experiments; S.-k.H. and S.C. performed the experiments; L.-q.Z. analyzed the data; M.-m.G. contributed reagents/materials/analysis tools; S.-k.H. wrote the paper.

Funding: This research was funded by [National Natural Science Foundation of China] grant number [51103006 and 51320105012].

Acknowledgments: We are thankful to Bao-chun Guo from the South China University of Technology and Wei-yu Cao from Beijing University of Chemical Technology for measurement of shape memory properties.

Conflicts of Interest: The authors declare no conflict of interest.

\section{References}

1. Weiss, R.A.; Izzo, E.; Mandelbaum, S. New Design of Shape Memory Polymers: Mixtures of an Elastomeric Ionomer and Low Molar Mass Fatty Acids and Their Salts. Macromolecules 2008, 41, 2978-2980. [CrossRef]

2. Lendlein, A.; Kelch, S. Shape-Memory Polymers. Angew. Chem. Int. Ed. 2002, 41, 2034-2057. [CrossRef]

3. Sun, L.; Huang, W.M.; Ding, Z.; Zhao, Y.; Wang, C.C.; Purnawali, H.; Tang, C. Stimulus-responsive shape memory materials: A review. Mater. Des. 2012, 33, 577-640. [CrossRef]

4. Leng, J.S.; Lan, X.; Liu, Y.L.; Du, S.Y. Shape-memory polymers and their composites: Stimulus methods and applications. Prog. Mater. Sci. 2011, 56, 1077-1135. [CrossRef]

5. Lendlein, A.; Jiang, H.Y.; Jünger, O.; Langer, R. Light-induced shape-memory polymers. Nature 2005, 434, 879-882. [CrossRef] [PubMed]

6. Fabrizio, Q.; Loredana, S.; Anna, S.E. Shape memory epoxy foams for space applications. Mater. Lett. 2012, 69, 20-23. [CrossRef]

7. Lendlein, A.; Behl, M.; Hiebl, B.; Wischke, C. Shape-memory polymers as a technology platform for biomedical applications. Expert Rev. Med. Devices 2010, 7, 357-379. [CrossRef]

8. Liu, Y.P.; Gall, K.; Dunn, M.L.; Mcculskey, P. Thermomechanics of shape memory polymer nanocomposites. Mech. Mater. 2004, 36, 929-940. [CrossRef]

9. Squeo, E.A.; Quadrini, F. Shape memory epoxy foams by solid-state foaming. Smart Mater. Struct. 2010, 19, 533-536. [CrossRef]

10. Liu, Y.Y.; Han, C.M.; Tan, H.F.; Du, X.W. Thermal, mechanical and shape memory properties of shape memory epoxy resin. Mater. Sci. Eng. A 2010, 527, 2510-2514. [CrossRef]

11. Yang, B.; Huang, W.M.; Li, C.; Li, L. Effects of moisture on the thermomechanical properties of a polyurethane shape memory polymer. Polymer 2006, 47, 1348-1356. [CrossRef]

12. Huang, W.M.; Yang, B.; An, L.; Li, C. Water-driven programmable polyurethane shape memory polymer: Demonstration and mechanism. Appl. Phys. Lett. 2005, 86, 114105-114108. [CrossRef]

13. Lee, K.M.; Koerner, H.; Vaia, R.A.; Bunning, T.J.; White, T.J. Light-activated shape memory of glassy, Azobenzene liquid crystalline polymer networks. Soft Matter 2011, 7, 4318-4324. [CrossRef]

14. Koerner, H.; Price, G.; Pearce, N.A.; Alxander, M.; Vaia, R.A. Remotely actuated polymer nanocomposites-stress-recovery of carbon-nanotube-filled thermoplastic elastomers. Nat. Mater. 2004, 3, 115. [CrossRef] [PubMed]

15. Xiao, Y.Y.; Gong, X.L.; Kang, Y.; Jiang, Z.C.; Zhang, S.; Li, B.J. Light-, pH- and thermal-responsive hydrogels with the triple-shape memory effect. Chem. Commun. 2016, 52, 10609-10612. [CrossRef]

16. Yang, J.; Wen, H.; Zhuo, H.; Chen, S.; Ban, J. A new type of photo-thermo staged-responsive shape-memory polyurethanes network. Polymers 2017, 9, 287-297. [CrossRef]

17. Ji, F.L.; Zhu, Y.; Hu, J.L.; Liu, Y.; Yeung, L.Y.; Ye, G.D. Smart polymer fibers with shape memory effect. Smart Mater. Struct. 2006, 15, 1547. [CrossRef] 
18. Du, F.P.; Ye, E.Z.; Yang, W.; Shen, T.H.; Tang, C.Y.; Xie, X.L.; Zhou, X.P.; Law, W.C. Electroactive shape memory polymer based on optimized multi-walled carbon nanotubes/polyvinyl alcohol nanocomposites. Compos. Part B 2015, 68, 170-175. [CrossRef]

19. Lu, H.B.; Liu, Y.J.; Gou, J.H.; Leng, J.S.; Du, S.Y. Synergistic effect of carbon nanofiber and carbon nanopaper on shape memory polymer composite. Appl. Phys. Lett. 2010, 96, 879. [CrossRef]

20. Lu, H.B.; Liu, Y.J.; Gou, J.H.; Leng, J.S.; Du, S.Y. Synergistic effect of carbon nanofiber and sub-micro filamentary nickel nanostrand on the shape memory polymer nanocomposite. Smart Mater. Struct. 2011, 20, 035017-035023. [CrossRef]

21. Lendlein, A.; Langer, R. Biodegradable, elastic shape-memory polymers for potential biomedical applications. Science 2002, 296, 1673-1676. [CrossRef] [PubMed]

22. Han, X.J.; Dong, Z.Q.; Fan, M.M.; Liu, Y.; Li, J.H.; Wang, Y.F.; Yuan, Q.J. pH-induced shape-memory polymers. Macromol. Rapid Commun. 2012, 33, 1055-1060. [CrossRef] [PubMed]

23. Meng, H.; Xiao, P.; Gu, J.; Wen, X.; Xu, J.; Zhao, C.; Zhang, J.; Chen, T. Self-healable macro-/microscopic shape memory hydrogels based on supramolecular interactions. Chem. Commun. 2014, 50, 12277-12280. [CrossRef] [PubMed]

24. Meng, H.; Zheng, J.; Wen, X.; Cai, Z.; Zhang, J.; Chen, T. Ph- and sugar-induced shape memory hydrogel based on reversible phenylboronic acid-diol ester bonds. Macromol. Rapid Commun. 2015, 36, 533-537. [CrossRef] [PubMed]

25. Yasin, A.; Li, H.Z.; Lu, Z.; Rehman, S.; Siddig, M.; Yang, H.Y. A shape memory hydrogel induced by the interactions between metal ions and phosphate. Soft Matter 2014, 10, 972. [CrossRef]

26. Ahn, S.; Deshmukh, P.; Kasi, R.M. Shape Memory Behavior of Side-Chain Liquid Crystalline Polymer Networks Triggered by Dual Transition Temperatures. Macromolecules 2010, 43, 7330-7340. [CrossRef]

27. Liu, C.D.; Chun, S.B.; Mather, P.T.; Zhang, L.; Haley, E.H.; Coughlin, E.B. Chemically Cross-Linked Polycyclooctene: Synthesis, Characterization, and Shape Memory Behavior. Macromolecules 2002, 35, 9868-9874. [CrossRef]

28. Liu, G.; Ding, X.; Cao, Y.; Zheng, Z.H.; Peng, Y.X. Shape Memory of Hydrogen-Bonded Polymer Network/Poly(ethylene glycol) Complexes. Macromolecules 2014, 37, 2228-2232. [CrossRef]

29. Cao, Y.P.; Guan, Y.; Du, J.; Luo, J.; Peng, Y.X.; Chan, A.S.C. Hydrogen-bonded polymer network-poly(ethylene glycol) complexes with shape memory effect. J. Mater. Chem. 2002, 12, 2957-2960. [CrossRef]

30. Liu, C.; Qin, H.; Mather, P.T. Review of progress in shape-memory polymers. J. Mater. Chem. 2007, 17, 1543-1558. [CrossRef]

31. Li, J.; Viveros, J.A.; Wrue, M.H.; Anthamatten, M. Shape-memory effects in polymer networks containing reversibly associating side-groups. Adv. Mater. 2007, 19, 2851-2855. [CrossRef]

32. Ware, T.; Hearon, K.; Lonnecker, A.; Wooley, K.L.; Maitland, D.J.; Voit, W. Triple-Shape Memory Polymers Based on Self-Complementary Hydrogen Bonding. Macromolecules 2012, 45, 1062. [CrossRef] [PubMed]

33. Chen, L.; Li, W.B.; Liu, Y.J.; Leng, J.S. Nanocomposites of epoxy-based shape memory polymer and thermally reduced graphite oxide: Mechanical, thermal and shape memory characterizations. Compos. Part B 2016, 91 , 75-82. [CrossRef]

34. Lendlein, A.; Behl, M. Shape-memory polymers. Mater. Today 2007, 10, 20-28. [CrossRef]

35. Zhao, X.Y.; Cao, Y.J.; Zou, H.; Li, J.; Zhang, L.Q. Structure and Dynamic Properties of Nitrile- Butadiene Rubber /Hindered Phenol Composites. J. Appl. Polym. Sci. 2011, 123, 3696-3702. [CrossRef]

36. Zhao, X.Y.; Xiang, P.; Cao, Y.J.; Tian, M.; Fond, H.; Jin, R.G.; Zhang, L.Q. Nitrile butadiene rubber/hindered phenol nanocomposites with improved strength and high damping performance. Polymer 2007, 48, 6056-6063. [CrossRef]

37. Jiang, H.Y.; Kelch, S.; Lendlein, A. Polymers Move in Response to Light. Adv. Mater. 2006, 18, 1471-1475. [CrossRef]

38. Parameswaranpillai, J.; Ramanan, S.P.; Jose, S.; Siengchin, S.; Magueresse, A.; Janke, A.; Pionteck, J. Shape memory properties of epoxy/PPO-PEO-PPO triblock copolymer blends with tunable thermal transitions and mechanical characteristics. Ind. Eng. Chem. Res. 2017, 56, 14069-14077. [CrossRef]

39. Kumar, K.S.S.; Biju, R.; Nair, C.P.R. Progress in shape memory epoxy resins. React. Funct. Polym. 2013, 73, 421-430. [CrossRef] 
40. Yu, R.; Yang, X.; Zhang, Y.; Zhao, X.; Wu, X.; Zhao, T.; Zhao, Y.; Huang, W. Three-dimensional printing of shape memory composites with epoxy-acrylate hybrid photopolymer. ACS Appl. Mater. Interfaces 2017, 9, 1820-1829. [CrossRef]

41. Wang, W.; Liu, D.; Liu, Y.; Leng, J.; Bhattacharyya, D. Electrical actuation properties of reduced graphene oxide paper/epoxy-based shape memory composites. Compos. Sci. Technol. 2015, 106, 20-24. [CrossRef]

42. Karger-Kocsis, J.; Kéki, S. Review of Progress in Shape Memory Epoxies and Their Composites. Polymers 2018, 10, 34. [CrossRef]

43. Xiao, D.L.; Zhao, X.Y.; Feng, Y.P.; Xiang, P.; Zhang, L.Q.; Wang, W.M. The structure and dynamic properties of thermoplastic polyurethane elastomer/hindered phenol hybrids. J. Appl. Polym. Sci. 2010, 116, 2143-2150. [CrossRef]

44. Ghobadi, E.; Heuchel, M.; Kratz, K.; Lendlein, A. Atomistic Simulation of the Shape-Memory Effect in Dry and Water Swollen Poly[(rac-lactide)-co-glycolide] and Copolyester Urethanes Thereof. Macromol. Chem. Phys. 2014, 215, 65-75. [CrossRef]

45. Ghobadi, E.; Heuchel, M.; Kratz, K.; Lendlein, A. Simulation of volumetric swelling of degradable poly[(rac-lactide)-co-glycolide] based polyesterurethanes containing different urethane-linkers. J. Appl. Biomater. Funct. Mater. 2013, 10, 293-301. [CrossRef] [PubMed]

46. Cao, Y.Y.; Mou, H.Y.; Shen, F.; Xu, H.Y.; Hu, G.H.; Wu, C.F. Hydrogenated nitrile butadiene rubber and hindered phenol composite. II. Characterization of hydrogen bonding. Polym. Eng. Sci. 2011, 51, $201-208$. [CrossRef]

47. Wu, C.F. Microstructural development of a vitrified hindered phenol compound during thermal annealing. Polymer 2003, 44, 1697-1703. [CrossRef]

48. Zhao, X.Y.; Lu, Y.L.; Xiao, D.L.; Wu, S.Z.; Zhang, L.Q. Thermoplastic Ternary Hybrids of Polyurethane, Hindered Phenol and Hindered Amine with Selective Two-Phase Dispersion. Macromol. Mater. Eng. 2009, 294, 345-351. [CrossRef]

(C) 2018 by the authors. Licensee MDPI, Basel, Switzerland. This article is an open access article distributed under the terms and conditions of the Creative Commons Attribution (CC BY) license (http:/ / creativecommons.org/licenses/by/4.0/). 